\title{
Calcifying Epithelial Odontogenic Tumor (Pindborg Tumor)
}

\author{
Punnya V. Angadi $\cdot$ K. Rekha
}

Received: 18 January 2011/Accepted: 3 February 2011/Published online: 16 February 2011

(C) Springer Science+Business Media, LLC 2011

\begin{abstract}
The calcifying epithelial odontogenic tumor is a benign epithelial tumor with characteristic clinical and histopathologic features. These features are discussed with a typical case presentation along with emphasis on newer variants and management strategies.
\end{abstract}

Keywords Calcifying epithelial odontogenic tumor . Pindborg tumor · Maxilla

\section{Case Report}

History

A 30 year old male presented to our institution with a gradually progressive swelling for the past year. Extraoral examination revealed a solitary diffuse swelling on the right side of face measuring around $3 \times 4 \mathrm{~cm}$ in size and obliterating the nasolabial fold. The swelling extended from $0.5 \mathrm{~cm}$ below the infraorbital margin to angle of the mouth and from the ala of the nose to the outer canthus mediolaterally. It was nontender and hard in consistency on palpation. Intraoral examination, revealed a solitary,

P. V. Angadi $(\square)$

Department of Oral Pathology and Microbiology, KLEVK Institute of Dental Sciences and Hospital, Belgaum 590010, Karnataka, India

e-mail: punnya_angadi@rediffmail.com

\section{K. Rekha}

Department of Oral Pathology and Microbiology, S.D.M College of Dental Sciences and Hospital, Dharwad 580009, Karnataka, India diffuse swelling extending from right maxillary lateral incisor to the second molar. There was obliteration of the buccal vestibule while palatally, the swelling extended from the gingival margin to the raphe region in relation to the right upper premolars and molars. The mucosa over the swelling was stretched but intact (Fig. 1a, b).

\section{Radiographic Features}

The panoramic radiograph revealed a well-defined radiolucency extending from the right maxillary lateral incisor to the 2nd molar with radiopacities dispersed within and associated with an impacted canine.

\section{Management}

The patient was taken for surgery and the lesion was removed in toto (Fig. 2a). The gross specimen measured $4 \times 3 \mathrm{~cm}$ and was a well-encapsulated round to ovoid cystic mass. It revealed regular borders, smooth surface and was firm to hard in consistency. Cut surface showed lesion to be granular with tooth completely embedded within the calcifications, which were sandy in consistency (Fig. 2b).

\section{Histopathology}

The hematoxylin and eosin stained sections revealed sheets of epithelial cells with prominent intercellular bridges, nuclear pleomorphism and hyperchromatism interspersed with eosinophilic amyloid like material and basophilic irregular to concentric calcifications. A diagnosis of calcifying epithelial odontogenic tumor was made by clinicopathologic correlation (Fig. 3a, b). 

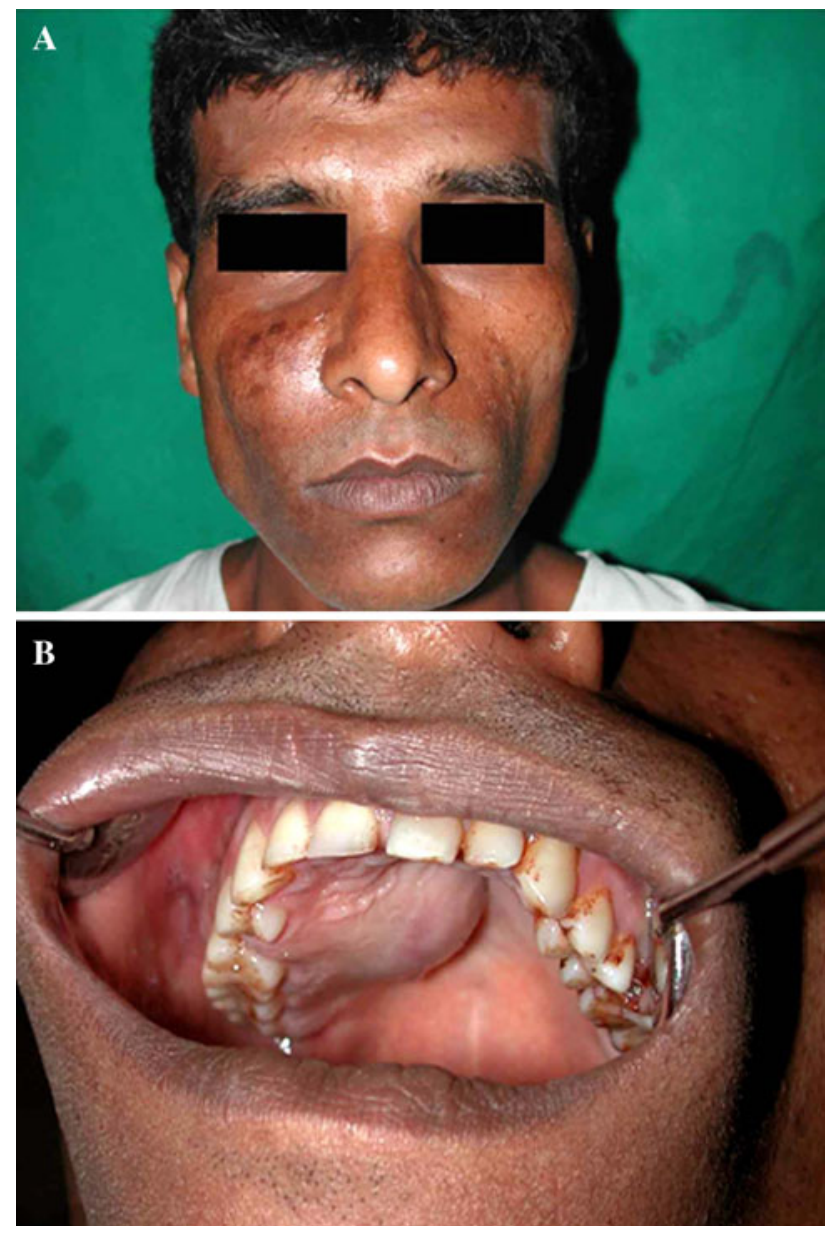

Fig. 1 A solitary diffuse extra-oral swelling on the right side of face obliterating the nasolabial fold (a). b Intraoral view of the tumor with expansion on buccal as well as the palatal aspect of the involved teeth

\section{Discussion}

Calcifying epithelial odontogenic tumor (CEOT) is an extremely rare benign odontogenic tumor; first described by Pindborg in 1955 . Since then, it is eponymously referred to as "Pindborg tumor" and accounts to around $1 \%$ of all the odontogenic tumors. It is a locally aggressive but slow growing neoplasm that occurs as intraosseous (96\%) and extraosseous (4\%) variants [1-3]. The histogenesis of this tumor remains elusive. It is postulated that CEOT arises from the stratum intermedium layer of the enamel organ while others believe that they arise from the remnants of dental lamina $[2,3]$. They tend to occur over a wide age range but usually predominate in the 3rd to 6th decades of life with almost equal sex predilection. The intraosseous CEOT are found primarily in the mandible (mandible: maxilla ratio 2:1), especially in the premolar and molar regions. Around $53 \%$ of these tumors are associated with unerupted teeth, most common being the mandibular
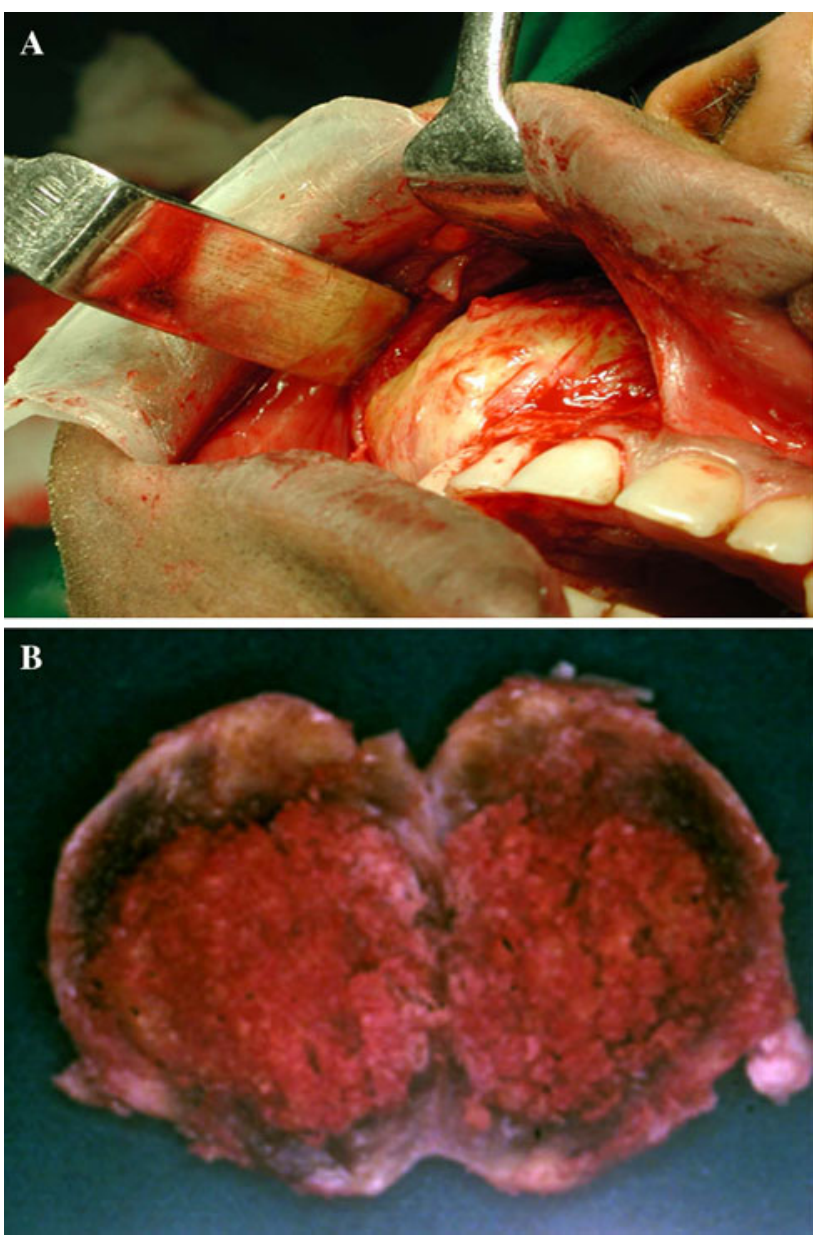

Fig. 2 a Intra-operative view of the lesion after surgical exposure. Macroscopic cut section demonstrates lesion to be granular with tooth completely embedded within the calcifications (b)

molars. The extraosseous variant exhibits a preponderance to the anterior gingival regions [1-5].

CEOT are slow growing, expansile, painless masses that cause expansion of the cortical plates but occasionally patients may report with pain, epistaxis, nasal stuffiness etc. The extraosseous variant usually presents as a nodular swelling. Radiographically, they demonstrate irregular unilocular or multilocular radiolucency containing radiopaque masses of varying sizes and opacity. If an unerupted tooth is associated with the tumor, the radiopacities tend to cluster near the tooth crown [3-5].

The intraosseous variant is often easily enucleated and varies in size from 1 to $4 \mathrm{~cm}$ in diameter. The mass is usually grayish white in color, bisection of which reveals multiple calcified particles which produce a crunching sound on cutting. The tumor may be solid or contain minute cystic spaces with the associated unerupted tooth being present within the tumor mass $[2,4]$.

The histopathology is unique consisting of sheets, nest and masses of polyhedral epithelial cells with abundant 

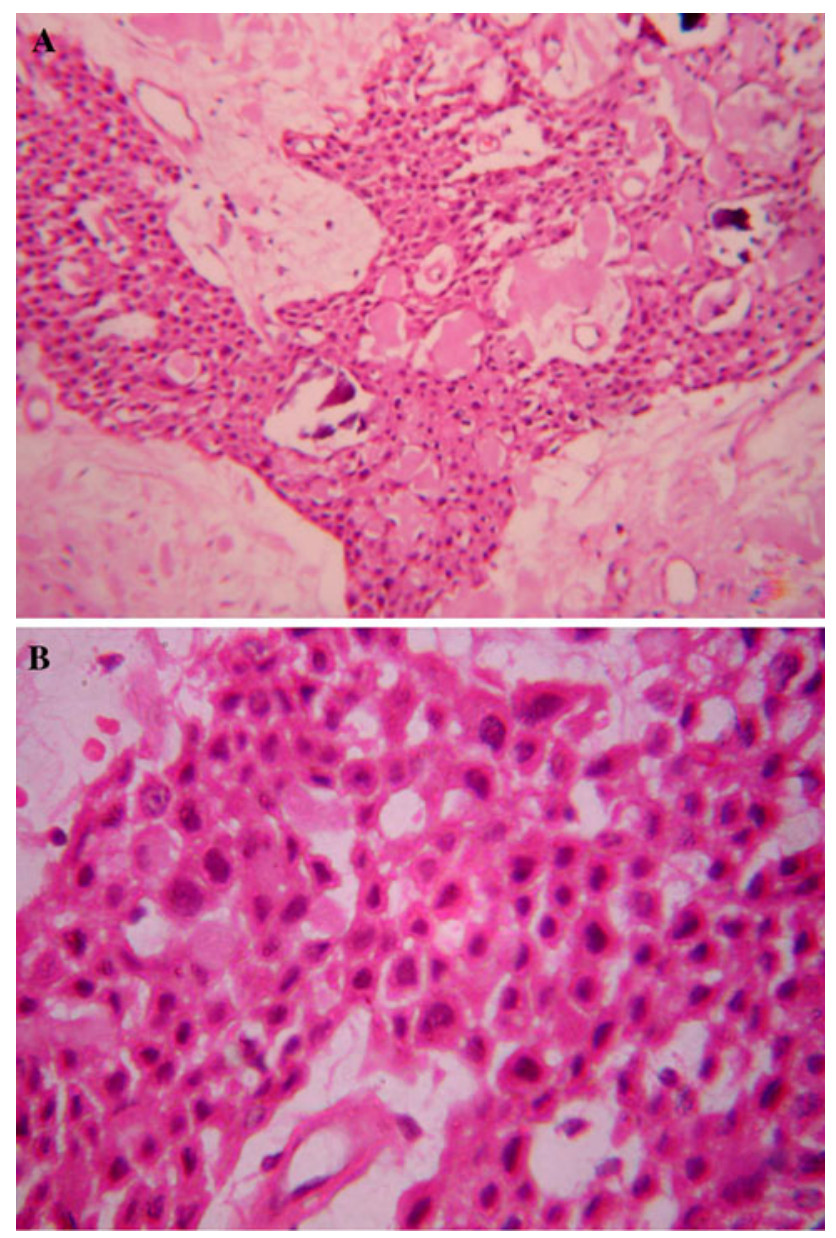

Fig. 3 a Photomicrograph demonstrates sheets of polyhedral cells interspersed with eosinophilic material and irregular calcification $(\mathrm{H} \& \mathrm{E} \times 100 \mathrm{~A})$. b High power view depicting the nuclear and cellular pleomorphism in the tumor cells $(\mathrm{H} \& \mathrm{E} \times 400)$

eosinophilic cytoplasm and prominent intercellular bridges. The cytomorphology of the cells may suggest a malignancy as they exhibit significant cellular and nuclear pleomorphism, prominent nucleoli and scattered giant cells. Nevertheless, mitotic figures are rare. A characteristic feature is presence of homogenous eosinophilic 'amyloid like' material interspersed between the cells; which stains positively with Congo red and exhibit apple green birefringence under polarized microscopy. This material undergoes calcification in the form of concentric 'Leisgang rings' that are pathognomic of this tumor [4]. Occasionally, extensive clear cell differentiation has also been reported [6]. The biochemical significance and origin of eosinophilic material is still controversial but several possibilities suggested include keratin, enamel matrix, amelogenin and enamelin [7, 8]. Recently, newer variants of CEOT like non-calcifying CEOT with langerhans cells, CEOT displaying cementum and bone like material and a combined adenomatoid odontogenic tumor and CEOT have also been described [9-11].

Marginal resection with a rim of normal tissue is the current therapy adopted. However, long term follow up is mandatory $[1,2,4]$. The recurrence rate reported is less than $15 \%$ which is mostly attributed to inadequate management [3]. Extremely rare carcinomatous transformation with regional lymph node involvement has been reported in elderly patients [12].

Conflict of interest None declared.

\section{References}

1. Franklin CD, Pindborg JJ. The calcifying epithelial odontogenic tumor: a review and analysis of 113 cases. Oral Surg Oral Med Oral Pathol. 1976;42:753-65.

2. Goode RK. Calcifying epithelial odontogenic tumor. Oral Maxillofac Surg Clin North Am. 2004;16:323-31.

3. Reichart PA, Philipsen HP, editors. Odontogenic tumors and Allied lesions. London: Quintessence Publishing; 2004. p. 43-59.

4. Neville BW, Damm DD, Allen CM. Odontogenic cyst and tumors. In: Gnepp DR, editor. Diagnostic surgical pathology of the head and neck. 1st ed. USA: W.B. Saunders Company; 2001. p. 633-4.

5. Houston GD, Fowler CB. Extra osseous calcifying epithelial odontogenic tumors: report of two cases and review of literature. Oral Surg Oral Med Oral Pathol Oral Radiol Endod. 1997;83:577-83.

6. Hicks MJ, Flaitz CM, Wong ME, Mc Daniel RK, Cagle PT. Clear cell variant of calcifying epithelial odontogenic tumor: case report and review of literature. Head Neck. 1994;16:272-7.

7. Saku T, Okabe H, Shimokawa H. Immunohistochemical demonstration of enamel proteins in odontogenic tumors. J Oral Pathol Med. 1992;21:113-9.

8. Aveil-Ronen S, Liokumovich P, Rahima D, Polak-Charcon S, Goldberg I, Horowitz A. The amyloid deposit in calcifying epithelial odontogenic tumor is immunoreactive to cytokeratins. Arch Pathol Lab Med. 2000;124:872-6.

9. Takata T, Ogawa I, Miyauchi M, Ijuhin N, Nikai H, Fujita M. Non-calcifying Pindborg tumor with langerhans cells. J Oral Pathol Med. 1993;22:378-83.

10. Slootweg PJ. Bone and cementum as stromal features in Pindborg tumor. J Oral Pathol Med. 1991;20:93-5.

11. Damm DD, White DK, Drummond JF, Poindexter JB, Henry BB. Combined epithelial odontogenic tumor; adenomatoid odontogenic tumor and calcifying epithelial odontogeic tumor. Oral Surg Oral Med Oral Pathol. 1983;55:487-96.

12. Veness MJ, Morgan G, Collins AP, Walker DM. Calcifying epithelial odontogeic (Pindborg) tumor with malignant transformation and metastaic spread. Head Neck. 2001;23:692-6. 